Meta

Journal des traducteurs

Translators' Journal

\title{
Glossaire des termes de presse
}

\section{Philippe Desjardins}

Volume 13, numéro 2, juin 1968

URI : https://id.erudit.org/iderudit/002552ar

DOI : https://doi.org/10.7202/002552ar

Aller au sommaire du numéro

Éditeur(s)

Les Presses de l'Université de Montréal

ISSN

0026-0452 (imprimé)

1492-1421 (numérique)

Découvrir la revue

Citer cet article

Desjardins, P. (1968). Glossaire des termes de presse. Meta, 13(2), 70-71.

https://doi.org/10.7202/002552ar

Ce document est protégé par la loi sur le droit d'auteur. L'utilisation des services d'Érudit (y compris la reproduction) est assujettie à sa politique d'utilisation que vous pouvez consulter en ligne.

https://apropos.erudit.org/fr/usagers/politique-dutilisation/
Cet article est diffusé et préservé par Érudit.

Érudit est un consortium interuniversitaire sans but lucratif composé de l’Université de Montréal, l'Université Laval et l'Université du Québec à Montréal. Il a pour mission la promotion et la valorisation de la recherche. https://www.erudit.org/fr/ 


\section{GLOSSAIRE DES TERMES DE PRESSE}

Le Centre de formation des journalistes, 29, rue du Louvre, Paris $2^{\mathrm{e}}$, vient de publier (1967) le Glossaire des termes de presse de Bernard Voyenne. Modeste (100 pages) et d'un prix modique ( $8 \mathrm{~F}$ ), cet ouvrage devrait être le vade-mecum de tous ceux qui font du journalisme, de près ou de loin. Bien que l'auteur se cléfende d'avoir épuisé le sujet: "nous ne nous flattons pas d'avoir été complet », déclare-t-il dans son Avertissement, il reste que ce petit glossaire fourmille de renseignements et mérite qu'on s'y arrête.

Ce qui surprend d'abord le Canadien français, toujours empressé à «faire » français autant que possible, c'est le nombre de mots anglais qui ont cours dans le métier; un effort concerté aurait suffi - on le verra - à leur chercher des équivalents. Pour être à peu près le seul qu'on puisse opposer à l'ouvrage mais c'est au métier qu'il faut en tenir rigueur plutôt qu'à l'auteur, qui se borne à consigner - ce reproche n'en est pas moins de taille, car la liste des termes visés est si importante qu'il s'impose de la reproduire: background, blimp, blitz, box, briefing, by-line, call-back, catch-phrase, close-up, col., color deck, comma, comics, curtain raiser, cut, dash, dateline, deadline, desk, deskman, dop sheet [sic], feature, flash, fudge, heavy, jingle, lead, leader, monitoring, morninger, new lead, off, offset, of the record, perchman, play-black, printing, query, quote, rewriter, round up, running, rush, scoop, script, shunter, spot, stock-shot, stop, story, streamer, stringer, sun-gun, tabloid, teletype-setter, ticker, truckman, undash, unquote, wordage.

L'auteur met en relief la nuance qui distingue stage et période d'essai, publicité et réclame ainsi que publicitaire et publiciste (les journalistes qui avaient détourné ce dernier mot des jurisconsultes se le sont fait dérober à leur tour par la gent publicitaire). Dans la même veine - ces choses étant au goût du jour l'auteur nous met en garde contre le danger de confondre la publicité rédactionnelle, l'information industrielle, le publi-reportage et le reportage publicitaire.

M. Voyenne nous apprend que l'homme de presse, selon sa spécialité, peut se présenter sous de nombreuses étiquettes: accrédité, agencier, articlier, attaché de presse, chambrier, chroniqueur, collaborateur, critique, éditorialiste, informateur, correspondant, correspondant à l'étranger, correspondant local, couloiriste, courriériste, détaché, échotier, envoyé spécial, fait-diversier, feuilletoniste, localier, nègre, nouvelliste, pigiste, journaliste présentateur, préfecturier, publiciste, rédacteur, rédacteur en chef, reporter, grand reporter, reporter caméraman, réviseur, salonnier, séancier, secrétaire d'édition, secrétaire de rédaction, soiriste, sténographe de presse, titreur, tournant ou tribunalier; les mal aimés de la profession portent les étiquettes de rubricard, baveux, canardier, gazetier ou pisse-copie, qui font surtout dans la salade, même s'ils ne sont pas toujours pisse-vinaigre.

Quelle que soit sa spécialité ou sa compétence, son papier, coiffé ou non d'un chapeau, prend l'une ou l'autre des formes suivantes: analytique, article, article de tête, article de fond, avant-papier, billet, bleu, bloc-notes, bouche-trou, bulletin, câble, chronique, colonne, commentaire, communiqué, compte rendu, condensé, continuité, dépêche, développement, écho, enquête, étude, exclusivité, fait divers, feuilleton, filet, forcé, grenouille, information, instantané, manchette, marronnier, médaillon, mondanités, mouture, nécrologie, passe-partout, pavé, 
revue de presse, profil, quotidienne, recension, rectificatif, régionale, reportage, reprend et complète, résumé, rubrique, serpent de mer, synthèse ou variété.

Sa copie peut être adaptée, aérée, anastasiée, bâtonnée, caviardée, collationnée, refondue, revisée (ou rewritée), sabrée ou bien virgulée. Elle peut s'accompagner d'un encadré ou d'un béquet et, bien entendu, peut aussi aboutir dans le courrier $d u$ cour, le courrier des lecteurs, le courrier littéraire, le courrier mondain, le carnet mondain, le carnet blanc ou encore le carnet rose.

Si la mémoire du journaliste vient à flancher ou encore si son inspiration se tarit, il n'a rien de mieux à faire que de dépouiller la canardothèque, ou encore le trombinoscope où il trouvera sans doute de la viande froide, sans jamais toutefois manquer au code d'honneur ou, en termes plus élégants, à la déontologie, car autrement il s'expose à se voir accusé de démarquage. Dans ce dernier cas, s'ill n'a pas à opposer un démenti, il risque du moins d'avoir à donner des éclaircissements, sinon à pondre un complément d'information ou peut-être même à publier une mise au point, un habillage ou un rectificatif.

Il tiendra ses renseignements de milieux autorisés, de milieux bien informés (ou simplement généralement bien informés) ou encore de source officieuse, même s'ils n'émanent pas toujours de source autorisée ou de bonne source. La carte bleue lui ouvrira les portes du concert, la rouge les coulisses du théâtre et la verte la loge des actrices de cinéma.

Selon ses fonctions, il relève du chef de rubrique, du directeur administratif, du directeur politique, du directeur de la rédaction ou du directeur de la publication.

Il côtoie des annonceurs et des annonciers, des correcteurs et des corrigeurs, des porteurs, des éculeux, des peaurougistes, des chameaux, des grouillots, voire des roule toujours. Si pendant qu'il s'occupe d'un accrochage ou d'une amorce... il vous propose de vous présenter une conasse ou bien une égyptienne italienne, vous auriez tort de tirer des conclusions hâtives; s'il vous parle d'un couillard, n'allez pas croire qu'il s'agit d'un collègue et si une collègue suggère de faire la poule, ne vous en scandalisez pas; dans le métier, un voleur n'est pas ce que vous pensez, car au lieu de passer par la fenêtre il en produit une. Enfin, l'auteur nous parle de singes et d'ours dans le journalisme, mais c'est là une autre question.

Le journaliste qui part en mission ne doit pas oublier son macaron, même s'il est muni de sa carte de journaliste et d'un coupe-file; s'il négrifie son tapuscrit, il doit se garder de le tartiner, car un collègue aura toujours assez de le dénégrifier avant la tombée. À son retour, ses frais professionnels lui sont remboursés sur présentation de sa note de frais, où il lui est loisible de les décompter de façon détaillée ou de les estimer forfaitairement.

Et puis, plus tard, s'il lui reste assez de souffle pour publier ses mémoires, il n'oubliera pas d'y mettre fin par le colophon, d'en adresser un prière d'insérer à la presse, sans toutefois aller jusqu'à exiger un justificatif.

Enfin, «quand la vague le désigne, l'appelant de sa grosse voix»- pour emprunter à Botrel de sa carrière, de s'être abstenu de sarrasiner et ... surtout d'avoir religieusement observé la consigne du concuvi* .

Philippe DesJardins

* Si le sens de ce mot vous échappe, il est conseillé de ne pas chercher à le préciser dans un salon! 